\title{
INDUÇÃO DE FITOALEXINAS E ATIVIDADE DE PEROXIDASES EM SORGO E SOJA TRATADOS COM EXTRATOS DE BASIDIOCARPOS DE PYCNOPORUS SANGUINEUS
}

\author{
C. Peiter-Beninca ${ }^{*}$, G. Franzener ${ }^{1}$, L. Assi ${ }^{1}$, L. Iurkiv ${ }^{1}$, B. Eckstein ${ }^{1}$, \\ V.C. Costa $^{1}$, M.A. Nogueira ${ }^{1}$, J.R. Stangarlin ${ }^{1 * *}$, K.R.F. Schwan-Estrada ${ }^{2 * *}$
}

${ }^{1}$ Universidade Estadual do Oeste do Paraná, Centro de Ciências Agrárias, Laboratório de Fitopatologia, CP 91, CEP 85960-000, Marechal Cândido Rondon, PR, Brasil. E-mail: camilabeninca@yahoo.com.br

\section{RESUMO}

\begin{abstract}
Este trabalho objetivou avaliar a indução de fitoalexinas e a atividade de peroxidases em sorgo e soja tratados com extratos de basidiocarpos dePycnoporus sanguineus. Os extratos diclorometânico, hexânico e etanólico com 100, 250,500 e 750 mg/L foram testados em relação à indução da produção de fitoalexinas e atividade de peroxidases em cotilédones de soja e mesocótilos estiolados de sorgo. Acibenzolar-S-metil (200 mg/L do produto comercial) e água destilada + Tween 20 foram utilizados como tratamentos controles positivo e negativo, respectivamente. Parafitoalexinas em mesocótilos de sorgo, o extrato hexânico $(750 \mathrm{mg} / \mathrm{L})$ proporcionou a maior indução, porém sem diferir significativamente do ASM. Para fitoalexinas em cotilédones de soja, os extratos de $P$. sanguineus não induziram atividade significativamente diferente dos tratamentos controles positivo e negativo, havendo uma tendência de supressão da síntese de gliceolina pelo extrato diclorometânico. Em relação às peroxidases, os extratos diclorometânico para sorgo e soja e etanólico para soja inibiram a atividade enzimática. A indução verificada para o extrato hexânico em sorgo não diferiu do controle ASM. A atividade específica de peroxidase em soja foi inibida pelo extrato etanólico e induzida pelo hexânico, mas sem diferença do tratamento com ASM. Esses resultados indicam o pequeno potencial destes extratos para a indução de resistência em patossistemas envolvendo sorgo e soja.
\end{abstract}

PALAVRAS-CHAVE: Indução de resistência, gliceolinas, deoxiantocianidinas.

\section{ABSTRACT}

PHYTOALEXIN INDUCTION AND PEROXIDASE ACTIVITY IN SORGUM AND SOYBEAN TREATED WITH BASIDIOCARP EXTRACTS OF PYCNOPORUS SANGUINEUS. This work aimed to verify the phytoalexin induction and the peroxidase activities in sorghum and soybean treated with extracts of $P$. sanguineus basidiocarp. To this end, dichloromethane, hexane and ethanol extracts, in concentrations of 100,250,500 and $750 \mathrm{mg} / \mathrm{L}$ were texted for phytoalexin induction and peroxidase activity in soybean cotyledons and sorghum etiolated mesocotyls. Acybenzolar-Smethyl (ASM) $(200 \mathrm{mg} / \mathrm{L}$ of commercial product) and distilled water + Tween $20(0.5 \%)$ were used as positive and negative control treatments, respectively. For the phytoalexin assay in sorghum mesocotyls, the hexanic extract in the concentration $750 \mathrm{mg} / \mathrm{L}$ provided the highest induction, however without differing significantly from ASM. For the phytoalexin assay in the soybean cotyledons, $P$. sanguineus extracts did not induce activity significantly different from the positive and negative control treatments, and showed a suppression of glyceollin synthesis for the dichloromethane extract. In relation to peroxidases, the dichloromethane extracts for sorghum and soybean and ethanol extract for soybean inhibited the enzymatic activity. The induction verified for the hexanic extract in sorghum was not different from the ASM control. The specific activity of peroxidase in soybeans was inhibited by the ethanol extract and it was induced by the hexanic, but with no differences in relation to the treatment with ASM. These results indicate the weak potential of these extracts for the induction of resistance in pathosystems involving sorghum and soybeans.

KEY WORDS: Induced resistance, glyceollins, deoxyanthocyanidins.

\footnotetext{
${ }^{2}$ Universidade Estadual de Maringá, Maringá, PR, Brasil.

*Parte da dissertação de mestrado do primeiro autor.

**Bolsistas do CNPq.
} 


\section{INTRODUÇÃO}

A indução de resistência corresponde à ativação do sistema de defesa latente nas plantas quando elas entram em contato com agentes chamados de eliciadores ou elicitores (PASCHOLATI; LeITE, 1995;SMITH, 1996). Entre os elicitores estão agentes bióticos, como microrganismos viáveis (STANGARLIN;PASCHOLATI,1994) ou inativos, ou abióticos, como ácido aminobutírico (CoHen, 1996), ácido 2,6-dicloroisonicotínico (HujwEGwn et al., 1996) e acibenzolar-S-metil, além de metais pesados, luz ultravioleta, ácido salicílico, fosfitos e silicatos, entre outros (CAVAlCANTI et al., 2005a). Esses mecanismos de resistência podem incluiroacúmulo decompostosfenólicos, defitoalexinas e de proteínas relacionadas à patogênese (como $\beta-1,3$ glucanase, quitinase e peroxidase) (CAVALCANTI et al., 2005b).

As fitoalexinas são compostos antimicrobianos de baixa massa molecular, sintetizadas e acumuladas nas plantas após estresses físicos, químicos ou biológicos, sendo capazes de reduzir ou impedir a atividade de agentes patogênicos (Pascholati; Leite, 1994;K UC, 1995; H AHN, 1996). Mais de 300 fitoalexinas já foram caracterizadas entre diferentes classes de compostos químicos como cumarina, diterpeno e flavonóide, entre outras, e têm sido identificadas em mais de 20 famílias de vegetais (SNYDER; NicHOLSON, 1990). A síntese de fitoalexinas ocorre em inclusões citoplasmáticas próximas ao local da tentativa de penetração do patógeno. Sua ação nos fungos se dá por desorganização dos conteúdos celulares, ruptura da membrana plasmática e inibição de enzimas fúngicas. Esses efeitos refletem-se na inibição da germinação e elongação do tubo germinativo e inibição do crescimento micelial (Lo et al., 1996). Em soja, a fitoalexina gliceolina (pterocarpanóide) mostra-se importante na interação dessa leguminosa com fitopatógenos (BURDEN; BAILEY, 1975). Em sorgo são produzidos compostos fenólicos em resposta a inoculação com fungos patogênicos ou tratamento com elicitores, sendo identificadas quatro fitoalexinas derivadas de antocianidinas (NicHOlson et al., 1987; HIPSKIND et al., 1990). Bioensaios com cotilédones de soja e com mesocótilos estiolados de sorgo são ferramentas importantes para se testar o efeito elicitor de um tratamento (STANGARLIN et al., 1999).

Além das fitoalexinas, as peroxidases podem atuar na resistência das plantas aos patógenos. As peroxidases participam de vários processos fisiológicos, catalisando a oxidação ea eventual polimerização de álcool hidroxicinâmico em presença de peróxido de hidrogênio, originando lignina, um importante mecanismo físico de defesa vegetal GASPAR et al., 1982), que contribui no fortalecimento das paredes celulares do hospedeiro. Alterações na atividade de peroxidases pelo tratamento com elicitores podem indicar o envolvimento destes na indução de resistência em plantas (TeNHAKen et al., 1995).

Entre os elicitores estão os extratos de plantas medicinais e óleos essenciais (compostos secundários) com propriedades antimicrobianas e/ou indutoras de resistência STANGARLIN et al., 1999; Schwan-Estrada et al., 2003; Schwan-Estrada; STANGARLIN, 2005), bem como os extratos obtidos de cogumelos (Di Piero et al., 2005).

Piccinin (2000), trabalhando com filtrados aquosos de basidiocarpo, píleo, estipee micélio do cogumelo Lentinula edodes (shiitake), verificou a ação elicitora desses tratamentos na produção de fitoalexinas do complexo das deoxiantocianidinas em sorgo e gliceolinas em soja. Fiori-Tutida (2003) observou que os extratos aquosos dos cogumelosL. edodese Agaricus blazei ('cogumelo do sol') estimularam a produção de fitoalexinas em sorgo e soja, induziram a produção de proteínas relacionadas à patogênese em trigo e ativaram rotas metabólicas para a formação de papilas em mesocótilos de trigo, indicando, assim, que esses cogumelos apresentam potencial como eliciadores de resposta de defesa em plântulas. DiPIERo (2003) constatou em seus experimentos com extratos aquosos de basidiocarpos de L.edodes eA.blazeiquehouveindução de resistência em plantas de pepino pelos dois cogumelos testados. Em plantas de tomate, apenasA.blazei apresentou potencial para o controle da bacteriose causada por Xanthomonas vesicatoria.

Outro basidiomiceto com potencial para controle de doenças é o Pycnoporus sanguineus ('orelha-de-pau' da família Polyporaceae) (NoBLES; FREW, 1962). A atividadeantimicrobiana destefungo tem sido verificada contra bactérias pela ação de compostos como 'poliporin' (Bose, 1946) e cinabarina (SMÂNIA JUNIOR et al., 2003).

Assi (2005) utilizou extratos aquosos de basidiocarpos de $P$. sanguineus para o controle de Colletotrichum lindemuthianum em ensaiosin vitro e no cultivo do feijoeiro, concluindo que houve controle do patógeno, tanto por atividade antimicrobiana direta, através da inibição da germinação de conídios, quanto por indução de resistência local e sistêmica, através da ativação de peroxidases. Esses extratos aquosos, entretanto, apresentaram-se inviáveis após 30 dias de armazenamento, mesmo sob refrigeração a $4{ }^{\circ} \mathrm{C}$, sendo colonizados por fungos e bactérias saprófitas, além de apresentarem oxidação e precipitação de compostos, havendo a necessidade, portanto, de se obter extratos mais estáveis.

Dessa forma, este trabalho objetivou avaliar a indução da produção de fitoalexinas e a atividade de peroxidases em sorgo e soja tratados com extratos de basidiocarpos de $P$. sanguineus obtidos com solventes orgânicos. 


\section{MATERIAL E MÉTODOS}

\section{Obtenção deP.sanguineus e produção dos extratos}

Basidiocarpos de $P$. sanguineus foram coletados nas matas da região Oeste do Paraná, secos em temperatura constante de $30^{\circ} \mathrm{C}$, triturados em moinho de esfera e o pó armazenado em geladeira à $4^{\circ} \mathrm{C}$. Uma porção de $160 \mathrm{~g}$ do fungo, na forma de pó seco de basidiocarpo, foi submetida à extração (aparelho Soxelet) com três solventes orgânicos de diferentes polaridades, hexano, etanol e diclorometano, em um procedimento cíclico durante $100 \mathrm{~h}$ para cada solvente, a $25^{\circ} \mathrm{C} \pm 2^{\circ} \mathrm{C}$, obtendo os compostos que foram utilizados nos experimentos. As soluções finais foram preparadas em quatro diferentes concentrações: $100,250,500$ e $750 \mathrm{mg} / \mathrm{L}$ em água contendo $0,5 \%$ de Tween 20.

\section{Produção defitoalexinas em mesocótilos desorgo}

Sementes de sorgo [Sorghum bicolor (L.) Moench] $\mathrm{cv}$. Brandes foram desinfestadas superficialmente com etanol $50 \%$ por 2 minelavadas emágua destilada. Posteriormente, foram enroladas entre folhas de papel de germinação umedecidas e incubadas no escuro por 3 dias à temperatura de $25^{\circ} \mathrm{C} \pm 2^{\circ} \mathrm{C}$. Após este período, as plântulas foram mantidas por $4 \mathrm{~h}$ na luz visando paralisar a elongação dos mesocótilos. Este processo resultou em plântulas com mesocótilos uniformemente elongados e adequados para o ensaio de produção de fitoalexinas (NichOLSON et al., 1988; YAMAOKA et al., 1990).

Os mesocótilos obtidos foram excisados $0,5 \mathrm{~cm}$ acima do nó escutelar e colocados em tubos de ensaio para microcentrífuga (quatro mesocótilos/tubo) contendo uma alíquota de $1 \mathrm{~mL}$ de cada concentração dos três extratos orgânicos de $P$. sanguineus. Como testemunhas, foram utilizados água destilada esterilizada com $0,5 \%$ de Tween 20 e o ativador de defesa vegetal acibenzolar-S-metil (ASM) $(200 \mathrm{mg} / \mathrm{L}$ do produto comercial) (Osswald et al., 2004). Os tubos de ensaio, abertos, foram mantidos em câmara úmida a $25^{\circ} \mathrm{C} \mathrm{sob}$ luz fluorescente (WulfF; PAschOLATI, 1999). Após 60h, os mesocótilos foram secos e os $5 \mathrm{~mm}$ basais de cada mesocótilo foram excisados e descartados. A porção superior $(2,5 \mathrm{~cm})$ (excetuando-se as folhas) foi pesada, cortada em pequenos segmentos e colocada em eppendorfs contendo $1,4 \mathrm{~mL}$ de metanol $80 \%$ acidificado $(0,1 \% \mathrm{HCl} ; \mathrm{v} / \mathrm{v})$. Os mesocótilos cortados foram mantidos a $4^{\circ} \mathrm{C}$ no metanol por $96 \mathrm{~h}$ para extração dos pigmentos e a absorbância determinada em espectrofotômetro a 480 nm (NicHOLSON et al.,1987; Nicholson et al., 1988). O material vegetal residual desta etapa (folhas) foi enrolado em papel alumínio e congelado em freezer para o teste de peroxidases.

\section{Produção de fitoalexinas em cotilédones de soja}

Sementes de soja (Glycine max L.) cultivar CD 202 (VIGo et al., 2001) foram desinfestadas, colocadas em areia esterilizada (autoclavada) e mantidas em casa de vegetação para germinação. Após 10 dias da semeadura, os cotilédones foram destacados das plântulas, lavados em água destilada, enxugados e cortados em secção aproximada de $1 \mathrm{~mm}$ de espessura e $6 \mathrm{~mm}$ de diâmetro a partir da superfície inferior. Quatro cotilédones foram colocados em placa de Petricontendo papel de filtro umedecido com água destilada estéril. Foi aplicada sobre cada cotilédone uma alíquota de $40 \mu \mathrm{L}$ de cada concentração $(100,250,500$ e $750 \mathrm{mg} / \mathrm{L})$ das três soluções do extrato de $P$. sanguineus além dos controles Tween 20 (0,5\%) e ASM $\left(200 \mathrm{mg} /\right.$ L do produto comercial Bion $\left.^{\circledR}\right)$. As placas de Petri foram mantidas à $25^{\circ} \mathrm{C}$ e escuro. Após $20 \mathrm{~h}$, os cotilédones foram transferidos para tubos de ensaio contendo $15 \mathrm{~mL}$ de água destilada esterilizada e deixados em agitação por $1 \mathrm{~h}$ para extração da fitoalexina formada. A absorbância foi determinada a 285 nm (Ayers et al., 1976; Ziegler; PontZen, 1982). Após esta etapa os cotilédones foram enrolados em papel alumínio e congelados em freezer a $-20^{\circ} \mathrm{C}$ para o teste de peroxidases.

\section{Atividade de peroxidases}

As amostras congeladas remanescentes dos testes de produção de fitoalexinas em sorgo e soja foram homogeneizadas em $4 \mathrm{~mL}$ de tampão fosfato (tampão de extração) $0,01 \mathrm{M}$ (pH 6,0) em almofariz de porcelana. O homogeneizado foi centrifugado a $6.000 \mathrm{~g} \mathrm{du}$ rante $20 \mathrm{~min}$. $\mathrm{O}$ sobrenadante obtido, considerado como a fração contendo as peroxidases solúveis, foi armazenado a $4^{\circ} \mathrm{C}$. A atividade das peroxidases foi determinada a $30^{\circ} \mathrm{C}$ em espectrofotômetro a $470 \mathrm{~nm}$. A mistura da solução consistiu de $2,9 \mathrm{~mL}$ de solução contendo $250 \mu \mathrm{L}$ de guaiacol e $306 \mu \mathrm{L}$ de peróxido de hidrogênio em $100 \mathrm{~mL}$ de tampão fosfato 0,01 M (pH 6,0) e 0,1 mL de preparação enzimática (Lusso; Pascholati, 1999). Os resultados foram expressos em variação de unidades de absorbância/min/mg de peso fresco ou mg de proteína. O teor de proteínas foi determinado conforme BRADFORD (1976).

\section{RESULTADOS E DISCUSSÃO}

\section{Indução de fitoalexinas em mesocótilos de sorgo}

A análise de variância demonstrou significância do teste $\mathrm{F}$, em nível de $5 \%$ de probabilidade, para a capacidade de induzir a produção de fitoalexinas em sorgo para os três extratos orgânicos testados. Entre- 
tanto, ao realizar o teste de Dunnett $(\mathrm{P} \leq 0,05)$, podese verificar que somente o extrato hexânico a $750 \mathrm{mg} / \mathrm{L}$ e o extrato etanólico a $100 \mathrm{mg} / \mathrm{L}$ de $P$. sanguineus tiveram atividade eliciadora efetiva, proporcionando valores de absorbância estatisticamente superiores ao da testemunha água (Tabela 1). Entretanto, esses valores foram 39 e $78 \%$, respectivamente, inferiores que o obtido para o ASM (testemunha positiva). Os demais tratamentos não apresentaram diferença significativa entre suas médias, porém diferiram da testemunha ASM, sendo verificados valores inferiores a esta.

As análises de regressão dos tratamentos indicaram ajustes lineares crescentes $(y=0,203 x+0,1213)$ $e(y=0,0032 x+0,3077)$ para os extratos diclorometânico e etanólico, respectivamente, enquanto que para o extrato hexânico o ajuste foi para uma equação de segundo grau, com incremento na indução de fitoalexinas diretamente proporcional às concentrações do extrato.

Para outros basidiomicetos também se tem verificado a capacidade de indução de fitoalexinas. FIORITutida (2003) observou que os extratos brutos dos cogumelos L. edodes e A. blazei possuem atividade eliciadora de fitoalexinas (deoxiantocianidinas) em mesocótilos de sorgo. Para P. sanguineus, no entanto, não há na literatura nenhum relato sobre o potencial indutor de fitoalexinas em sorgo.

\section{Indução de fitoalexinas em cotilédones de soja}

Pela análise de variância, em nível de 5\% de probabilidade, não se observaram diferenças significativas no teste $\mathrm{F}$ (tratamentos entre si e com as testemunhas) em todos os extratos orgânicos testados para a produção de fitoalexinas em cotilédones de soja (Tabela 2).

Para o extrato diclorometânico observou-se uma curva de regressão com $\mathrm{R}^{2} \mathrm{de} 0,67$ eo melhor ajuste dos dados procedeu-se com uma equação de segundo grau. Não houve ajuste satisfatório dos dados para os extratos hexânico e etanólico.

Pode-se concluir que a média da produção de fitoalexinas foi maior em mesocótilos estiolados de sorgo (0,44 de absorbância/g.p.f.) do que em cotilédones de soja (0,031 deabsorbância/g.p.f.). Essa comparação está de acordo com os resultados de Piccinin (2000) que, utilizando diferentes extratos de L.edodes, constatou maior acúmulo defitoalexinas em mesocótilos de sorgo do que em cotilédones de soja.

FIORI-TUTIDA (2003) observou resultados diferentes deste trabalho, verificando que os extratos aquosos dos cogumelos L. edodes e A. blazei possuem atividade eliciadora de fitoalexinas em cotilédones de soja, visto que há indução de gliceolina em soja pelos polissacarídeos presentes em extratos aquosos. Há evidências de receptores em soja que se ligam a glucanas acarretando a indução de fitoalexinas. $\mathrm{O}$ gênero Agaricus proporcionou um maior acúmulo de fitoalexinas gliceolinas (0,41 de absorbância/g.p.f.) do que o gêneroLentinula (0,16 deabsorbância/g.p.f.). Já para mesocótilos de sorgo, o gênero Lentinula proporcionou maior acúmulo de fitoalexinas do que Agaricus.

Atividade de peroxidases em mesocótilos estiolados de sorgo

Pode-se observarque para o extrato diclorometânico houve uma supressão da atividade de peroxidases a partir da concentração de $100 \mathrm{mg} / \mathrm{L}$. A curva de regressão obteve um $R^{2}$ relativamente baixo $(0,53)$ e a equação que melhor explicou os dados foi a de 2 ograu. Pode-se concluir pelo teste F ( $5 \%$ de probabilidade) que os dados não diferiram significativamente entre si e também não diferiram da testemunha (Tabela 3). Este extrato apresentou, na média, a menor atividade de peroxidases (1,96 absorbância/min/g.p.f.), em comparação aos outros dois extratos.

Com relação ao extrato hexânico, a maior atividade de peroxidases foi com concentração de $250 \mathrm{mg} / \mathrm{L}$ (2,98 absorbância/min/g.p.f.), mas sem diferença significativa da testemunha, que foi de 2,74 absorbância/ min/g.p.f., e dos outros extratos. O melhor ajuste dos dados foi com uma equação de 2 o grau.

O extrato etanólico revelou uma diminuição na atividade de peroxidases conforme aumentou sua concentração, não havendo um ajuste satisfatório dos dados, já que o valor do $\mathrm{R}^{2}$ foibaixo. A produçãomédia de peroxidases foi de 2,1 absorbância/min/g.p.f.

\section{Atividade de peroxidases em cotilédones de soja}

Para o extrato diclorometânico, verificou-se a maior atividade de peroxidases (5,16 absorbância/min/ g.p.f.) na concentração de $100 \mathrm{mg} / \mathrm{L}$ de $P$. sanguineus, superando a testemunha ASM em $30 \%$. O ponto de mínima atividade foi em $500 \mathrm{mg} / \mathrm{L}$, com 3,38 de absorbância/min/g.p.f. Contudo, ao realizar a análise de variância, pode-se verificar que o teste $\mathrm{F}$ não acusou significância ao nível de $5 \%$ de probabilidade, para os dados entre si e com a testemunha (Tabela 4). O melhor ajuste da curva foi realizado com uma equação de $2 \mathfrak{o}$ grau. Para o extrato hexânico, não houve ajuste satisfatório dos dados.

Os dados do extrato etanólico indicam uma supressão da atividade de peroxidases proporcional ao aumento da concentração utilizada. O melhor ajuste dos dados foi com a equação de 20 grau. Novamente, a análise de variância não demonstrou significância pelo teste $\mathrm{F}$ entre os tratamentos e a testemunha. 
Tabela 1 - Produção de fitoalexinas em mesocótilos estiolados de sorgo pelo tratamento com extratos de $P$. sanguineus obtidos em hexano, etanol e diclorometano.

\begin{tabular}{llllll}
\hline \multirow{2}{*}{ Extratos } & \multicolumn{5}{c}{ Concentrações $(\mathrm{mg} / \mathrm{L})$} \\
\cline { 2 - 6 } & 0 & 100 & 250 & 500 & 750 \\
\hline Hexano & $0,14^{*} \mathrm{a}$ & $0,42 \mathrm{~b}^{-}$ & $0,29 \mathrm{a}^{-}$ & $0,51 \mathrm{a}^{-}$ & $1,78 \mathrm{a}^{\text {ns }}$ \\
Etanol & $0,14 \mathrm{a}$ & $0,61 \mathrm{a}^{\text {ns }}$ & $0,17 \mathrm{a}^{-}$ & $0,27 \mathrm{a}^{-}$ & $0,29 \mathrm{~b}^{-}$ \\
Diclorometano & $0,14 \mathrm{a}$ & $0,17 \mathrm{~b}^{-}$ & $0,14 \mathrm{a}^{-}$ & $0,29 \mathrm{a}^{-}$ & $0,28 \mathrm{~b}^{-}$ \\
\hline ASM** $^{* *}$ & 2,91 & & & &
\end{tabular}

$\mathrm{ASM}^{* *} \quad 2,91$

*Valores representam a absorbância $(480 \mathrm{~nm}) /$ grama de peso fresco;

**Acibenzolar-S-metil (200 mg do produto comercial/L); Médias seguidas de mesma letra na coluna não diferem entre si pelo teste de Tukey a 5\%;

(ns): sem diferença significativa da testemunha ASM (Dunnett 5\%);

${ }^{(+)} \mathrm{e}^{(-)}$: diferenças significativas da testemunha ASM, sendo superior ou inferior a esta, respectivamente.

Tabela 3 - Atividade de peroxidases em mesocótilos estiolados de sorgo pelo tratamento com extratos de $P$. sanguineus obtidos em hexano, etanol e diclorometano.

\begin{tabular}{llllll}
\hline Extratos & \multicolumn{5}{c}{ Concentrações $(\mathrm{mg} / \mathrm{L})$} \\
\cline { 2 - 6 } & 0 & 100 & 250 & 500 & 750 \\
\hline Hexano & $2,58^{*} \mathrm{a}$ & $2,51 \mathrm{a}^{\text {ns }}$ & $2,98 \mathrm{a}^{\text {ns }}$ & $2,76 \mathrm{a}^{\text {ns }}$ & $2,84 \mathrm{a}^{\text {ns }}$ \\
Etanol & $2,58 \mathrm{a}$ & $2,21 \mathrm{a}^{\text {ns }}$ & $1,94 \mathrm{ab}^{\text {ns }}$ & $2,18 \mathrm{a}^{\text {ns }}$ & $1,99 \mathrm{a}^{\text {ns }}$ \\
Diclorometano & $2,58 \mathrm{a}$ & $2,28 \mathrm{a}^{\text {ns }}$ & $1,56 \mathrm{~b}^{-}$ & $1,91 \mathrm{a}^{\text {ns }}$ & $1,80 \mathrm{a}^{\text {ns }}$ \\
\hline ASM $^{* *}$ & 2,74 & & & & \\
\hline
\end{tabular}

*Valores representam a variação nas unidades de absorbância (470 nm)/min/grama peso fresco;

**Acibenzolar-S-metil (200 mg do produto comercial/L); Médias seguidas de mesma letra na coluna não diferem entre si pelo teste de Tukey a 5\%;

(ns): sem diferença significativa da testemunha ASM (Dunnett 5\%);

${ }^{(+)} \mathrm{e}^{(-)}$: diferenças significativas da testemunha ASM, sendo superior ou inferior a esta, respectivamente.

Em relação ao experimento com atividade de peroxidases, pode-se concluir que houve maior indução pelos extratos de P. sanguineusemcotilédones de soja do que em mesocótilos de sorgo. O valor mínimo de atividade de peroxidases em cotilédones de soja foi $100 \%$ maior do que o valor mínimo produzido em mesocótilos de sorgo.

Assi (2005), em trabalho com feijoeiro tratado com extratos aquosos de basidiocarpos de P. sanguineus, concluiu que houve ativação de mecanismos de defesa, principalmente para extrato em concentração de
Tabela 2 - Produção de fitoalexinas em cotilédones de soja pelo tratamento com extratos de P. sanguineus obtidos em hexano, etanol e diclorometano.

\begin{tabular}{llllll}
\hline Extratos & \multicolumn{5}{c}{ Concentrações $(\mathrm{mg} / \mathrm{L})$} \\
\cline { 2 - 6 } & 0 & 100 & 250 & 500 & 750 \\
\hline Hexano & $0,031^{*} \mathrm{a}$ & $0,032^{\text {ns }}$ & $0,025^{\mathrm{ns}}$ & $0,030^{\text {ns }}$ & $0,032^{\text {ns }}$ \\
Etanol & $0,031 \mathrm{a}$ & $0,023^{\text {ns }}$ & $0,035^{\text {ns }}$ & $0,27 a^{-}$ & $0,026^{\text {ns }}$ \\
Diclorometano & $0,031 \mathrm{a}$ & $0,031^{\text {ns }}$ & $0,037^{\text {ns }}$ & $0,29 a^{-}$ & $0,025^{\text {ns }}$ \\
\hline ASM $^{* *}$ & 0,031 & & & &
\end{tabular}

*Valores representam a absorbância $(285 \mathrm{~nm})$ / grama de peso fresco;

**Acibenzolar-S-metil (200 mg do produto comercial/L); Médias seguidas de mesma letra na coluna não diferem entre si pelo teste de Tukey a 5\%;

(ns): sem diferença significativa da testemunha ASM (Dunnett 5\%).

Tabela 4 - Atividade de peroxidases em cotilédones de soja pelo tratamento com extratos de $P$. sanguineus obtidos em hexano, etanol e diclorometano.

\begin{tabular}{llllll}
\hline Extratos & \multicolumn{5}{c}{ Concentrações $(\mathrm{mg} / \mathrm{L})$} \\
\cline { 2 - 6 } & 0 & 100 & 250 & 500 & 750 \\
\hline Hexano & $2,58^{*} \mathrm{a}$ & $3,96 \mathrm{a}^{\text {ns }}$ & $3,10 \mathrm{a}^{\text {ns }}$ & $3,68 \mathrm{a}^{\text {ns }}$ & $3,27 \mathrm{a}^{\text {ns }}$ \\
Etanol & $2,58 \mathrm{a}$ & $4,49 \mathrm{a}^{\text {ns }}$ & $4,21 \mathrm{a}^{\text {ns }}$ & $3,73 \mathrm{a}^{\text {ns }}$ & $3,80 \mathrm{a}^{\text {ns }}$ \\
Diclorometano & $2,58 \mathrm{a}$ & $5,16 \mathrm{a}^{\text {ns }}$ & $3,91 \mathrm{a}^{\text {ns }}$ & $3,38 \mathrm{a}^{\text {ns }}$ & $4,33 \mathrm{a}^{\text {ns }}$ \\
\hline ASM $^{* *}$ & 3,95 & & & &
\end{tabular}

ASM** 3,95

*Valores representam a variação das unidades de absorbância (470 nm)/ min/grama peso fresco;

**Acibenzolar-S-metil (200 mg do produto comercial/L); Médias seguidas de mesma letra na coluna não diferem entre si pelo teste de Tukey a $5 \%$;

(ns): sem diferença significativa da testemunha ASM (Dunnett 5\%).

$20 \%$, através de incremento local e sistêmico na atividade e atividade específica de peroxidases, o que pode ter contribuído para a redução da severidade da antracnose causada por C. lindemuthianum.

Comrelaçãoaatividadeespecífica deperoxidaseem cotilédones de soja, pode-se observar com o extrato diclorometânico o maior valor (na concentração de 250 mg/L) superandoa testemunha ASMem 30\% (Tabela 5). Para o extrato hexânico houve incremento na atividade de peroxidases, com ajuste para equação de 2 o grau e pico de atividade na concentração de $500 \mathrm{mg} / \mathrm{L}$. 
Tabela 5 - Atividade específica de peroxidases em cotilédones de soja pelo tratamento com extratos de $P$. sanguineus obtidos em hexano, etanol e diclorometano.

\begin{tabular}{llllll}
\hline \multirow{2}{*}{ Extratos } & \multicolumn{5}{c}{ Concentrações $(\mathrm{mg} / \mathrm{L})$} \\
\cline { 2 - 6 } & 0 & 100 & 250 & 500 & 750 \\
\hline Hexano & $2,08^{* a}$ & $1,35 \mathrm{~b}^{-}$ & $1,13 \mathrm{a}^{\mathrm{ns}}$ & $2,48 \mathrm{a}^{\mathrm{ns}}$ & $2,10 \mathrm{a}^{\mathrm{ns}}$ \\
Etanol & $2,08 \mathrm{a}$ & $2,06 \mathrm{ab}^{\mathrm{ns}}$ & $1,29 \mathrm{a}^{\mathrm{ns}}$ & $0,30 \mathrm{~b}^{-}$ & $0,23 \mathrm{~b}^{-}$ \\
Diclorometano & $2,08 \mathrm{a}$ & $2,45 \mathrm{a}^{\mathrm{ns}}$ & $2,68 \mathrm{a}^{\mathrm{ns}}$ & $2,34 \mathrm{a}^{\mathrm{ns}}$ & $2,54 \mathrm{a}^{\mathrm{ns}}$ \\
\hline ASM $^{* *}$ & 2,07 & & & & \\
\hline
\end{tabular}

*Valores representam a variação das unidades de absorbância $(470 \mathrm{~nm}) / \mathrm{min} / \mu \mathrm{g}$ de proteína;

**Acibenzolar-S-metil (200 mg do produto comercial/L); Médias seguidas de mesma letra na coluna não diferem entre si pelo teste de Tukey a 5\%;

(ns): sem diferença significativa da testemunha ASM (Dunnett 5\%);

${ }^{(+)} \mathrm{e}^{(-)}$: diferenças significativas da testemunha ASM, sendo superior ou inferior a esta, respectivamente.

O tratamento com extrato etanólico demonstrou uma inibição da atividade de peroxidase proporcional ao aumento da concentração utilizada. Os dados se ajustaram a uma equação de 20 grau. Para as concentrações de 500 e $750 \mathrm{mg} / \mathrm{L}$ a atividade específica foi significativamente inferior à obtida no tratamento com ASM. O teste de Tukey $(\mathrm{P} \leq 0,05)$ das concentrações 500 e $750 \mathrm{mg} / \mathrm{L}$ demonstrou que os extratos hexânico e diclorometânico não diferiram para a testemunha ASM, porém diferiram estatisticamente do extrato com etanol, com valores até nove vezes maior para estas concentrações.

Apesar da enzima peroxidase estar relacionada a eventos envolvendo a indução de resistência (CAVALCANTIet al., 2005b), não há um padrão definido para seu comportamento, o qual depende do tipo de indutor ou eliciador, sua concentração, tempo após a sua aplicação na planta e patossistema em estudo.

VIECELLI(2008) também observou redução na atividade de peroxidase em feijoeiro (IAPAR 81 Carioca) tratado com extrato aquoso de basidiocarpo de $P$. sanguineus a $10 \%$ e inoculado com Pseudocercospora griseola (sin.: Phaeoisariopsis griseola), patógeno causador da Mancha Angular. O mesmo extrato, na concentração de $20 \%$, incrementou a atividade de peroxidase aos quatro dias após a inoculação (DAI), mas a reduziu aos cinco e sete DAI. Para o extrato aquoso de micélio de $P$. sanguineus efiltrado decultura desse basidiomiceto, esse autor também verificou indução de atividade de peroxidase aos quatro DAI, com posterior redução aos cinco e sete DAI. Tal comportamento foi observado tanto na terceira folha de feijoeiro, que foi tratada e posteriormente inoculada com o patógeno, quanto na quarta folha apenas inoculada, demonstrando a sistemicidade desse efeito.

Esse comportamento oscilante na atividade de peroxidase também foi observado por BALDO (2008) utilizando esses mesmo extratos aquosos em feijoeiro (IAPAR 81 Carioca) inoculado com C.lindemuthianum.

Para os extratos de basidiocarpos de P. sanguineus, esse comportamento oscilatório de indução e repressão da atividade de peroxidase pode estar relacionado à quantidadedecompostoseliciadores presentes nele.IURKIV et al. (2008), trabalhando com cinco picos protéicos e um pico de carboidrato, obtidos por cromatografia de filtração em gel a partir de extrato aquoso de basidiocarpo de $P$. sanguineus a $20 \%$ (peso seco/volume), observaram que esses picos isoladamente proporcionaram incrementos de até $47 \%$ na atividade de peroxidase em cotilédones de soja, enquanto que o extrato não fracionado apresentou característica supressora para esta enzima, com redução de $62 \%$ para sua atividade específica.

\section{CONCLUSÕES}

Os extratos orgânicos diclorometânico, hexânico e etanólico de basidiocarpos de $P$. sanguineus não possuem atividade indutora de fitoalexinas em cotilédones de soja, mas induzem a síntese de deoxiantocianidinas em mesocótilos de sorgo. Os extratos orgânicos de basidiocarpos de P. sanguineus, diclorometânico para sorgo e soja e etanólico para soja inibem a atividade de peroxidase, enquanto que o extrato hexânico incrementa a atividade e a atividade específica para sorgo e soja, respectivamente.

\section{AGRADECIMENTOS}

Os autores agradecem ao Conselho Nacional de Desenvolvimento Científico e Tecnológico (CNPq), à Fundação Araucária e à Financiadora de Estudos e Projetos (FINEP) pelo auxílio financeiro.

\section{REFERÊNCIAS}

ASSI, L. Controle de Colletotrichum lindemuthianum (Sacc. Et Magn.) Scrib na cultura do feijão (Phaseolus vulgaris L.) pelo extrato do cogumelo Pycnoporus sanguineus (L.ex Fr.).2005.51p. Dissertação (Mestrado) - Universidade Estadual do Oeste do Paraná/UNIOESTE, Marechal Cândido Rondon, 2005.

AYERS, A.R.; EBEL, J.; FINELLI, F.; BERGER, N.; ALBERSHEIM, P. Host-pathogen interactions. IX. Quantitative assays of elicitor activity and characterization of the elicitor present in the extracellular medium of cultures of Phytophthora megasperma var. sojae. Plant Physiology, v.57, p.751-759, 1976. 
BALDO, M. Aspectos histológicos e bioquímicos da indução de resistência em feijoeiro e atividade antifúngica por derivados de Pycnoporus sanguineus. 2008. 83p. Dissertação (Mestrado) - Universidade Estadual do Oeste do Paraná/UNIOESTE, Marechal Cândido Rondon, 2008.

BOSE, S.R. Antibiotics in a Polyporus (Polystictus sanguineus). Nature, v.158, p.292-296, 1946.

BRADFORD, M.M. A rapid and sensitive method for the quantifivation of microgram quantities of protein utiling the principle of protein-dye binding. Analytical Biochemistry, v.72, p.248-254, 1976.

BURDEN, R.J.; BAILEY, J.A. Structure of the phytoalexin from soybean. Phytochemistry, v.14, p.1389-1390, 1975.

CAVALCANTI, L.S.; DI PIERO, R.M.; CIA, P.; PASCHOLATI, S.F.; RESENDE, M.L.V.; ROMEIRO, R.S. (Ed.). Indução de resistência em plantas a patógenos e insetos. Piracicaba: FEALQ, 2005a. 263p.

CAVALCANTI, L.S.; BRUNELLI, K.R.; STANGARLIN, J.R. Aspectos bioquímicos e moleculares da resistência induzida. In: CAVALCANTI, L.S.; DI PIERO, R.M.; CIA, P.; PASCHOLATI, S.F.; RESENDE, M.L.V.; ROMEIRO, R.S. (Ed.). Indução de resistência em plantas a patógenos e insetos. Piracicaba: FEALQ, 2005b. p.81-124.

COHEN, Y. Induced resistance against fungal diseases by aminobutyric acids. In: LYR, H.; RUSSEL, P.E.; SISLER, H.D. (Ed.). Modern fungicides and antifungal compounds. Andover: Intercept, 1996. p.461-466.

DI PIERO, R.M. Potencial dos cogumelos Lentinula edodes (Shiitake) e Agaricus blazei (Cogumelo-do-Sol) no controle de doenças em plantas de pepino, maracujá e tomate, e a purificação parcial de compostos biologicamente ativos. 2003. 157p. Tese (Doutorado) - Escola Superior de Agricultura "Luiz de Queiroz", Universidade de São Paulo, Piracicaba, 2003.

DI PIERO, R.M.; GARCIA JUNIOR, D.; TONUCCI, N.M. Indutores bióticos. In: R.S. (Ed.). Indução de resistência em plantas a patógenos e insetos. Piracicaba: FEALQ, 2005. p.29-50.

FIORI-TUTIDA, A.C.G. Uso de extratos dos Cogumelos Lentinula edodes (Berk.) Pegler e Agaricus blazei (Murrill) ss. Heinem no controle in vitro de Puccinia recondita f. sp. tritici e na indução de resistência em trigo à Bipolaris sorokiniana. 2003. 112p. Tese (Doutorado) - Universidade Estadual de Maringá, Maringá, 2003.

GASPAR, T.H.; PENEL, C.; THORPE, T.; GREPPIN, H. Peroxidases 1970-1980: a survey of their biotecnical and physiological roles in higher plants. Geneva: Universidade de Geneva, Centro de Botanique, 1982. 324p.

HAHN, M.G. Microbial elicitors and their receptors in plants. Annual Review of Phytopathology, n.34, p.387-412, 1996.
HIJWEGWN, T.; VERHAAR, M.A.; ZADORKS, J.C. Resistance to Sphaerotheca pannosa in roses induced by 2,6-dichloroisonicotinic acid. Plant Pathology, v.45, p.631-635, 1996.

HIPSKIND, J.; HANAU, R.; LEITE, B.; NICHOLSON, R.L. Phytoalexin accumulation in sorghum: identification of an apigeninidin acyl ester. Physiological and Molecular Plant Pathology, v.36, p.381396, 1990.

IURKIV, L.; BALDO, M.; STANGARLIN, J.R.; FRANZENER, G.; KUHN, O.J.; MEINERZ, C.C. Atividade de peroxidases em cotilédones de soja tratados com frações de Pycnoporus sanguineus obtidas a partir de cromatografia de filtração em gel (CFG). Summa Phytopathologica, v.34, p.91-92, 2008.

KUC, J. Phytoalexins, stress metabolism, and disease resistance in plants. Annual Review of Phytopathology, v.33, p.275-297, 1995.

LO, S.C.; WEIERGANG, I.; BONHAM, C.; HIPSKIND, J.; WOOD, K.; NICHOLSON, R.L. Phytoalexin accumulation in sorghum: identification of a methyl ether of luteolinidin. Physiological and Molecular Plant Pathology, v.49, n.1, p.21-31, 1996.

LUSSO, M.F.G.; PASCHOLATI, S.F. Achtivty and isoenzymatic pattern of soluble peroxidases in maize tissues after mechanical injury or fungal inoculation. Summa Phytopathologica, v.25, p.244-249, 1999.

NICHOLSON, R.L.; KOLLIPARA, S.S.; VINCENT, J.R.; LYONS, P.C.; CADENA-GOMEZ, G. Phytoalexin synthesis by the sorghum mesocotyl in response to infection by pathogenic and nonpathogenic fungi. Proceedings of the National Academy of Sciences, v.84, p.5520-5524, 1987.

NICHOLSON, R.L.; JAMIL, F.F.; SNYDER, B.A.; LUE, W.L.; HISPKIND, J. Phytoalexin synthesis in the juvenile sorghum leaf. Physiological and Molecular Plant Pathology, v.33, p.271-278, 1988.

NOBLES, M.K.; FREW, B.P. Studies in wood-inhabiting hymenomycetes. The genus Pycnoporus Karst. Cannadian Journal of Botany, v.40, p.987-1016, 1962.

OSSWALD, W.F.; STANGARLIN, J.R.; NICHOLSON, R.L.; BRUMMER, M.; WULFF, N.A.; DI PIERO, R.M.; PICCININ, E.; DI CIERO, L.; HOTO, F.V.; PASCHOLATI, S.F. The effect of Acibenzolar-S-methyl on phytoalexins and PR-protein induction on sorgum mesocotyls and on Colletotrichum sublineolum. Summa Phytopathologica, v.30, n.4, p.415-420, 2004.

PASCHOLATI, S.F.; LEITE, B. Mecanismos bioquímicos de resistência às doenças. Revisão Anual de Patologia de Plantas, v.2, p.1-51, 1994. 
PASCHOLATI, S.F.; LEITE, B. Hospedeiro: Mecanismo de resistência, 1995. In: BERGAMIN FILHO, A.; KIMATI, H.; AMORIM, L. (Ed.). Manual de fitopatologiaprincípios e conceitos. São Paulo: Ed. Agronômica Ceres, 1995. v.1, cap.22, p.417-454.

PICCININ, E. Potencial de preparações do cogumelo comestível "shiitake" (Lentinula edodes) no controle de fitopatógenos fúngicos, bacterianos e virais em sorgo, maracujá e fumo. 2000. 160p. Tese (Doutorado) - Escola Superior de Agricultura “Luis de Queiroz", Universidade de São Paulo, Piracicaba, 2000.

SCHWAN-ESTRADA, K.R.F.; STANGARLIN, J.R.; CRUZ, M.E.S. Uso de plantas medicinais no controle de doenças de plantas. Fitopatologia Brasileira, v.8, p. S54S56, 2003.

SCHWAN-ESTRADA, K.R.F.; STANGARLIN, J.R. Extratos e óleos essenciais de plantas medicinais na indução de resistência. In: CAVALCANTI, L.S.; DI PIERO, R.M.; CIA, P.; PASCHOLATI, S.F.; RESENDE, M.L.V.; ROMEIRO, R.S. (Ed.). Indução de resistência em plantas a patógenos e insetos. Piracicaba: FEALQ, 2005. p.125-138.

SMÂNIA JUNIOR, A.; MARQUES, C.J.S.; SMÂNIA, E.F.A.; ZANETTI, C.R.; CAROBREZ, S.G.; TRAMONTE, R.; LEITE, C.L. Toxicity and antiviral activity of cinnabarin obtained from Pycnoporus sanguineus (Fr.) Murr. Phytotherapy Research, n.17, p.1069-1072, 2003.

SMITH, C.J. Accumulation of phytoalexins: defence mechanism and stimulus response system. New Phytologist, v.132, n.1, p.1-45, 1996.

SNYDER, B.; NICHOLSON, R.L. Synthesis of phytoalexins in sorghum as a site response to fungal ingress. Science, v.248, p.1637-1639, 1990.

STANGARLIN, J.R.; PASCHOLATI, S.F. Proteção de plântulas de milho pipoca contra Exserobilum turcicum pelo uso de Saccharomyces cerevisiae. Summa Phythopatologica, v.20, p.16-21, 1994.
STANGARLIN, J.R.; SCWAN-ESTRADA, K.R.F.; CRUZ, M.E.S.; NOZAKI, M.H. Plantas Medicinais - Plantas medicinais e controle alternativo de fitopatógenos. Biotecnologia Ciência \& Desenvolvimento, v.2, n.11, p.16-21, 1999.

TENHAKEN, R.; LEVINE, A.; BRISSON, L.F.; DIXON, R.A.; LAMB, C. Function of the oxidative burst in hypersensitive disease resistance. Proceedings of the National Academy of Sciences of the United States of America, v.92, p.4158-4163, 1995.

VIECELLI, C.A. Controle da mancha angular e análise bioquímica de resistência em feijoeiro tratado com extratos de Pycnoporus sanguineus. 2008. 60p. Dissertação (Mestrado) - Universidade Estadual do Oeste do Paraná/UNIOESTE, Marechal Cândido Rondon, 2008.

VIGO, S.C.; FRANZENER, G.; STANGARLIN, J.R., SCHWAN-ESTRADA, K.R.F.; CRUZ, M.E.S. Indução de gliceolina em soja e inibição da germinação de conídios de Microsphaera diffusa pela tritura vegetal de Pfaffia glomerata. Fitopatologia Brasileira, v.26, p.351, 2001. Suplemento.

WULFF, N.A.; PASCHOLATI, S.F. Caracterização parcial de elicitores de fitoalexinas em sorgo isolados de Saccharomyces cerevisiae. Fitopatologia Brasileira, v.24, n.3, p.428-435, 1999.

YAMAOKA, N.; LYONS, P.C.; HIPSKIND, J.; NICHOLSON, R.L. Elicitor of sorghum phytoalexin synthesis from Colletotrichum graminicola. Physiological and Molecular Plant Pathology, v.37, p.255-270, 1990.

ZIEGLER, E.; PONTZEN, R. Specific inhibition of glucan-elicited glyceolin accumulation in soybeans by extracellular mannan-glycoprotein of Phytophthora megasperma f.sp. glycinea. Physiological Plant Pathology, v.20, p.321-331, 1982.

Recebido em 16/5/07

Aceito em 21/8/08 